\title{
Androgen-Deprivation Therapy and Cardiovascular Disease Risk - The Role of Exercise in Prostate Cancer Treatment
}

\author{
Bradley Wall* \\ School of Psychology and Exercise Science, Murdoch University, Murdoch, WA, Australia
}

Keywords: prostate cancer, exercise, androgen-deprivation therapy, cardiovascular disease

Reduced levels of physical activity and increased levels of fatigue are commonly reported in prostate cancer patients treated with androgen-deprivation therapy (ADT) (1) that in turn reduces functional capacity. Reductions are seen in cardiorespiratory endurance, upper and lower body strength and endurance, and physical components of quality of life (1-3), which lead to inhibiting activities of daily living. In addition to these well-established side effects, cardiovascular disease (CVD) risk is now being increasingly associated with ADT $(4,5)$. Keating et al. (6) report ADT use is associated with higher risks of incident diabetes, coronary heart disease, acute myocardial

OPEN ACCESS

Edited by:

Masaki Shiota,

Kyushu University, Japan

Reviewed by:

Kouji Izumi,

Kanazawa University, Japan

Hung-Ming Lam,

University of Washington, USA

*Correspondence:

Bradley Wall

b.wall@murdoch.edu.au

Specialty section:

This article was submitted to Genitourinary Oncology,

a section of the journal

Frontiers in Oncology

Received: 05 August 2016

Accepted: 23 August 2016

Published: 19 September 2016

Citation:

Wall B (2016) Androgen-Deprivation

Therapy and Cardiovascular Disease

Risk - The Role of Exercise in

Prostate Cancer Treatment.

Front. Oncol. 6:200.

doi: 10.3389/fonc.2016.00200 infarction, and sudden cardiac death. The increasing body of literature supports an earlier report indicating that CVD is the most common form of mortality in men with prostate cancer, and not the actual cancer itself (7).

Exercise has been shown to be effective for improving surgical outcomes, reducing symptom experience, managing side effects, improving psychological health, maintaining physical function, and reducing fat gain and muscle and bone loss in cancer patients (8) and hence has the potential to reduce CVD risk factors. Studies in the past have used aerobic exercise (9), resistance exercise $(9,10)$, or a combination of aerobic and resistance exercise (11). Exercise programs have also differed in method of delivery with some home based (12) while others are group based in a clinic setting $(11,13)$ making comparisons as to the best treatment mode of exercise difficult.

\section{RESISTANCE TRAINING}

Resistance exercise improves muscle strength and function and has been shown to be an effective intervention against sarcopenia (14). This exercise mode also leads to improvements in functional capacity and quality of life while reducing disability in individuals with and without CVD $(15,16)$. In prostate cancer patients undergoing treatment, studies have shown positive effects of resistance exercise on reducing musculoskeletal treatment side effects, decreasing fatigue, and improving quality of life $(10,13)$, despite a compromised hormonal profile (17). Segal and colleagues (10) had patients complete resistance exercises three times per week for 12 weeks and reported upper and lower body muscular fitness improvements of 42 and $32 \%$, respectively, whereas Galvao et al. (13) had patients undergo resistance exercise two times per week for 20 weeks and reported significant improvements in upper body muscular strength (chest press $40 \%$ and seated row $42 \%$ ), lower body strength (leg press $96 \%$ ), functional performance (400 m walk $7.4 \%$, stair climb $10.4 \%$, and chair rise $27 \%)$, and balance $(7.8 \%)$.

Improvements in muscle mass, such as those seen by Galvao et al. (11), are important not only in terms of mobility and functional performance but also in terms of assisting glucose 
disposal (18). Muscle stimulates insulin sensitivity and accounts for up to $80 \%$ of insulin-dependent glucose uptake (19). Numerous clinical studies have shown resistance training to lower the percentage of glycated hemoglobin and increase glucose disposal as well as favorably impact CVD risk factors in elderly individuals $(20,21)$. Srikanthan and Karlamangla (22) conducted a cross-sectional analysis of the National Health and Nutritional Examination Survey III data to investigate the possible correlation between relative muscle mass and insulin resistance and prediabetes. After adjusting for age, ethnicity, sex, and generalized and central obesity, the authors found for every $10 \%$ increase in skeletal muscle index (skeletal muscle mass relative to total body mass) was associated with an $11 \%$ reduction in insulin resistance and a $12 \%$ relative reduction in prediabetes. This correlation was stronger in non-diabetic patients (22) and was not just limited to the lower, sarcopenic end of the muscle mass distribution in the population, suggesting that increases in muscle mass, even above average levels, was associated with additional protection against insulin resistance and diabetes. Given the association of insulin resistance and CVD, the metabolic effect of muscle mass gained as a result of resistance training has the ability to alter CVD risk (23), particularly in an ADT-treated population where reductions in muscle mass have previously been reported (24).

\section{AEROBIC TRAINING}

Studies employing aerobic training only interventions have primarily utilized breast cancer patients, with promising outcomes reported in physical function, fatigue mitigation, and quality of life (25-27). Of the aerobic intervention studies in prostate cancer patients, radiotherapy has been the most common treatment modality $(28,29)$ with one study utilizing ADT-treated prostate cancer patients (9). Segal et al. (9) reported beneficial effects of the aerobic training for both fatigue mitigation and maintenance of aerobic fitness.

With regard to non-cancer patients, it is well established that cardiorespiratory fitness attenuates the mortality risk associated with metabolic syndrome in healthy men, independent of body mass (30), indicating that cardiorespiratory fitness is of greater importance than body mass per se. High cardiorespiratory fitness levels have also been found to attenuate the increased arterial stiffness in patients with metabolic syndrome. Increases in arterial stiffness, independent of age and blood pressure, have been reported in men receiving ADT (31-33) highlighting the need for prescribed aerobic exercise programs focused on improving cardiorespiratory fitness to offset the metabolic related treatment toxicities in ADT-treated patients.

\section{REFERENCES}

1. Galvao DA, Taaffe DR, Spry N, Joseph D, Turner D, Newton RU. Reduced muscle strength and functional performance in men with prostate cancer undergoing androgen suppression: a comprehensive cross-sectional investigation. Prostate Cancer Prostatic Dis (2009) 12(2):198-203. doi:10.1038/ pcan.2008.51

\section{COMBINED AEROBIC AND RESISTANCE TRAINING}

Although there are studies that have investigated the effects that resistance training programs and aerobic training programs have on prostate cancer patients undergoing treatment, very few have utilized a combined aerobic and resistance training intervention with prostate cancer patients undergoing ADT. Culos-Reed et al. (12) were one of the first study to attempt to employ a combined aerobic and resistance training program in ADT-treated prostate cancer patients; however, the study was a low-intensity homebased intervention and hence lacked the control of a laboratorybased intervention. This apparent lack of control may have been the reason for a lack of statistically significant differences. Galvao et al. (11) were the first group to conduct a clinic-based supervised, randomized controlled study to evaluate the combined effects of a resistance and low volume aerobic exercise program in men undergoing ADT. Galvao et al. (11) reported favorable changes in total body and regional lean mass as well as improvements in muscular strength and functional performance outcomes. Cardiorespiratory capacity only showed borderline improvement, but this was thought to be a result of the low level of aerobic exercise prescribed. Participants undertook 30-40 min of aerobic exercise per week, which is well below 150 min recommended by the American Heart Association for good health. However, the promising aspect of this study was that despite the low dose of aerobic exercise prescribed, borderline changes were still seen in cardiorespiratory capacity.

\section{CONCLUSION}

Given the recent attention that ADT and the associated CVD risk have received, it is clear that exercise interventions specifically targeting CVD risk outcomes are required. Previous studies have targeted resistance training or aerobic training alone and have reported positive outcomes specific to the training modality. What is now needed are exercise interventions that apply sound aerobic and resistance training principles in combination to prevent the development of CVD in men undergoing ADT for the treatment of prostate cancer.

\section{AUTHOR CONTRIBUTIONS}

BW is responsible for all aspects of this opinion piece.

\section{ACKNOWLEDGMENTS}

The above content originated from the author's $\mathrm{PhD}$ thesis (34).

2. Alibhai SMH, Breunis H, Timilshina N, Johnston C, Tomlinson G, Tannock I, et al. Impact of androgen-deprivation therapy on physical function and quality of life in men with nonmetastatic prostate cancer. J Clin Oncol (2010) 28(34):5038-45. doi:10.1200/JCO.2010.30.8742

3. Basaria S, Lieb J, Tang AM, DeWeese T, Carducci M, Eisenberger M, et al. Longterm effects of androgen deprivation therapy in prostate cancer patients. Clin Endocrinol (Oxf) (2002) 56(6):779-86. doi:10.1046/j.1365-2265.2002.01551.x 
4. Miller K. Cardiovascular risks of androgen deprivation therapy for prostate cancer. Urology (2016) 55(5):627-31. doi:10.1007/s00120-015-0021-1

5. Zareba P, Duivenvoorden W, Leong DP, Pinthus JH. Androgen deprivation therapy and cardiovascular disease: what is the linking mechanism? Ther $A d v$ Urol (2016) 8(2):118-29. doi:10.1177/1756287215617872

6. Keating NL, O'Malley AJ, Smith MR. Diabetes and cardiovascular disease during androgen deprivation therapy for prostate cancer. J Clin Oncol (2006) 24(27):4448-56. doi:10.1200/JCO.2006.06.2497

7. Lu-Yao G, Stukel TA, Yao SL. Changing patterns in competing causes of death in men with prostate cancer: a population based study. J Urol (2004) 171(6 Pt 1):2285-90. doi:10.1097/01.ju.0000127740.96006.1a

8. Newton R, Galvão D. Exercise in prevention and management of cancer. Curr Treat Options Oncol (2008) 9(2):135-46. doi:10.1007/s11864-008-0065-1

9. Segal RJ, Reid RD, Courneya KS, Sigal RJ, Kenny GP, Prud'Homme DG, et al. Randomized controlled trial of resistance or aerobic exercise in men receiving radiation therapy for prostate cancer. J Clin Oncol (2009) 27(3):344-51. doi:10.1200/JCO.2007.15.4963

10. Segal RJ, Reid RD, Courneya KS, Malone SC, Parliament MB, Scott CG, et al. Resistance exercise in men receiving androgen deprivation therapy for prostate cancer. J Clin Oncol (2003) 21(9):1653-9. doi:10.1200/JCO.2003. 09.534

11. Galvao DA, Taaffe DR, Spry N, Joseph D, Newton RU. Combined resistance and aerobic exercise program reverses muscle loss in men undergoing androgen suppression therapy for prostate cancer without bone metastases: a randomized controlled trial. J Clin Oncol (2010) 28(2):340-7. doi:10.1200/ JCO.2009.23.2488

12. Culos-Reed SN, Robinson JW, Lau H, Stephenson L, Keats M, Norris S, et al. Physical activity for men receiving androgen deprivation therapy for prostate cancer: benefits from a 16-week intervention. Support Care Cancer (2009) 18(5):591-9. doi:10.1007/s00520-009-0694-3

13. Galvao DA, Nosaka K, Taaffe DR, Spry N, Kristjanson LJ, McGuigan MR, et al. Resistance training and reduction of treatment side effects in prostate cancer patients. Med Sci Sports Exerc (2006) 38(12):2045-52. doi:10.1249/01. mss.0000233803.48691.8b

14. Frontera WR, Meredith CN, O'Reilly KP, Knuttgen HG, Evans WJ. Strength conditioning in older men: skeletal muscle hypertrophy and improved function. J Appl Physiol (1988) 64(3):1038-44.

15. Williams MA, Haskell WL, Ades PA, Amsterdam EA, Bittner V, Franklin BA, et al. Resistance exercise in individuals with and without cardiovascular disease: 2007 update: a scientific statement from the American Heart Association Council on Clinical Cardiology and Council on Nutrition, Physical Activity, and Metabolism. Circulation (2007) 116(5):572-84. doi:10.1161/ CIRCULATIONAHA.107.185214

16. Hunter GR, McCarthy JP, Bamman MM. Effects of resistance training on older adults. Sports Med (2004) 34(5):329-48. doi:10.2165/00007256200434050-00005

17. Galvao DA, Nosaka K, Taaffe DR, Peake J, Spry N, Suzuki K, et al. Endocrine and immune responses to resistance training in prostate cancer patients. Prostate Cancer Prostatic Dis (2008) 11(2):160-5. doi:10.1038/sj.pcan.4500991

18. Ferrara CM, Goldberg AP, Ortmeyer HK, Ryan AS. Effects of aerobic and resistive exercise training on glucose disposal and skeletal muscle metabolism in older men. J Gerontol A Biol Sci Med Sci (2006) 61(5):480-7. doi:10.1093/ gerona/61.5.480

19. DeFronzo RA, Jacot E, Jequier E, Maeder E, Wahren J, Felber JP. The effect of insulin on the disposal of intravenous glucose. Results from indirect calorimetry and hepatic and femoral venous catheterization. Diabetes (1981) 30(12):1000-7. doi:10.2337/diab.30.12.1000

20. Zanuso S, Jimenez A, Pugliese G, Corigliano G, Balducci S. Exercise for the management of type 2 diabetes: a review of the evidence. Acta Diabetol (2010) 47(1):15-22. doi:10.1007/s00592-009-0126-3

21. Holten MK, Zacho M, Gaster M, Juel C, Wojtaszewski JFP, Dela F. Strength training increases insulin-mediated glucose uptake, GLUT4 content, and insulin signaling in skeletal muscle in patients with type 2 diabetes. Diabetes (2004) 53(2):294-305. doi:10.2337/diabetes.53.2.294

22. Srikanthan P, Karlamangla AS. Relative muscle mass is inversely associated with insulin resistance and prediabetes. Findings from the third National Health and Nutrition Examination Survey. J Clin Endocrinol Metab (2011) 96(9):2898-903. doi:10.1210/jc.2011-0435

23. Srikanthan P, Horwich TB, Tseng CH. Relation of muscle mass and fat mass to cardiovascular disease mortality. Am J Cardiol (2016) 117(8):1355-60. doi:10.1016/j.amjcard.2016.01.033

24. Galvao DA, Spry NA, Taaffe DR, Newton RU, Stanley J, Shannon T, et al. Changes in muscle, fat and bone mass after 36 weeks of maximal androgen blockade for prostate cancer. Br J Urol (2008) 102(1):44-7. doi:10.1111/j. 1464-410X.2008.07539.x

25. Campbell A, Mutrie N, White F, McGuire F, Kearney N. A pilot study of a supervised group exercise programme as a rehabilitation treatment for women with breast cancer receiving adjuvant treatment. Eur J Oncol Nurs (2005) 9(1):56-63. doi:10.1016/j.ejon.2004.03.007

26. Pinto BM, Frierson GM, Rabin C, Trunzo JJ, Marcus BH. Home-based physical activity intervention for breast cancer patients. J Clin Oncol (2005) 23(15):3577-87. doi:10.1200/JCO.2005.03.080

27. Mock V, Dow KH, Meares CJ, Grimm PM, Dienemann JA, Haisfield-Wolfe $\mathrm{ME}$, et al. Effects of exercise on fatigue, physical functioning, and emotional distress during radiation therapy for breast cancer. Oncol Nurs Forum (1997) 24(6):991-1000.

28. Windsor PM, Nicol KF, Potter J. A randomized, controlled trial of aerobic exercise for treatment-related fatigue in men receiving radical external beam radiotherapy for localized prostate carcinoma. Cancer (2004) 101(3):550-7. doi:10.1002/cncr.20378

29. Monga U, Garber SL, Thornby J, Vallbona C, Kerrigan AJ, Monga TN, et al. Exercise prevents fatigue and improves quality of life in prostate cancer patients undergoing radiotherapy. Arch Phys Med Rehabil (2007) 88(11):1416-22. doi:10.1016/j.apmr.2007.08.110

30. Katzmarzyk PT, Church TS, Blair SN. Cardiorespiratory fitness attenuates the effects of the metabolic syndrome on all-cause and cardiovascular disease mortality in men. Arch Int Med (2004) 164(10):1092-7. doi:10.1001/ archinte.164.10.1092

31. Smith JC, Bennett S, Evans LM, Kynaston HG, Parmar M, Mason MD, et al. The effects of induced hypogonadism on arterial stiffness, body composition, and metabolic parameters in males with prostate cancer. J Clin Endocrinol Metab (2001) 86(9):4261-7. doi:10.1210/jcem.86.9.7851

32. Dockery F, Bulpitt CJ, Agarwal S, Donaldson M, Rajkumar C. Testosterone suppression in men with prostate cancer leads to an increase in arterial stiffness and hyperinsulinaemia. Clin Sci (2003) 104(2):195-201. doi:10.1042/ cs1040195

33. Dockery F, Rajkumar C, Agarwal S, Waxman J, Bulpitt CJ. Androgen deprivation in males is associated with decreased central arterial compliance and reduced central systolic blood pressure. J Hum Hypertens (2000) 14(6):395-7. doi:10.1038/sj.jhh. 1001028

34. Wall BA. Exercise as Medicine: Reversing Treatment Toxicities in Prostate Cancer Patients. Perth, WA: Edith Cowan University (2013).

Conflict of Interest Statement: The author declares that the research was conducted in the absence of any commercial or financial relationships that could be construed as a potential conflict of interest.

Copyright $\odot 2016$ Wall. This is an open-access article distributed under the terms of the Creative Commons Attribution License (CC BY). The use, distribution or reproduction in other forums is permitted, provided the original author $(s)$ or licensor are credited and that the original publication in this journal is cited, in accordance with accepted academic practice. No use, distribution or reproduction is permitted which does not comply with these terms. 